\title{
Theoretical guidelines for editing ecological communities
}

\author{
Vu Nguyen ${ }^{1}$ and Dervis Can Vural ${ }^{1}$ \\ ${ }^{1}$ University of Notre Dame
}

May 5, 2020

\begin{abstract}
Having control over species abundances and community resilience is of great interest for experimental, agricultural, industrial and conservation purposes. Here, we theoretically explore the possibility of manipulating ecological communities by modifying pairwise interactions. Specifically, we establish which interaction values should be modified, and by how much, in order to alter the composition or resilience of a community towards a favorable direction. While doing so, we also take into account the experimental difficulties in making such modifications by including in our optimization process, a cost parameter, which penalizes large modifications. In addition to prescribing what changes should be made to interspecies interactions given some modification cost, our approach also serves to establish the limits of community control, i.e. how well can one approach an ecological goal at best, even when not constrained by cost.
\end{abstract}

\section{Hosted file}

control_optimization-4.pdf available at https://authorea.com/users/296060/articles/424928theoretical-guidelines-for-editing-ecological-communities 